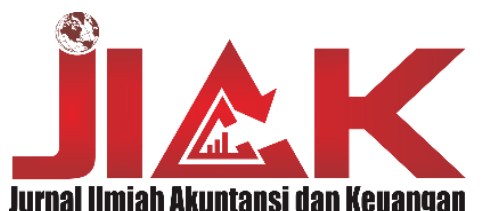

http://journal.stieputrabangsa.ac.id/index.php/jiak

ISSN: 2580-510X/ P-ISSN: 2548-9453

ARTICLE INFORMATION

Received September $29^{\text {th }} 2020$

Accepted June $8^{\text {th }} 2021$

Published Jun $12^{\text {th }} 2021$

DOI:

https://doi.org/10.32639/jiak. v9i2.665

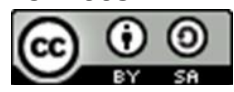

\section{Pengaruh Pelaksanaan Penagihan Pajak Terhadap Pencairan Tunggakan Pajak Di Kantor Pelayanan Pajak Pratama Palembang Ilir Barat}

\author{
Masayu Luthfiah Siti Khodijah ${ }^{1}$, Yuhanis Ladewi ${ }^{2}$, Fadhil Yamaly ${ }^{3}$ \\ 1,2,3) Universitas Muhammadiyah Palembang \\ email: msyluthfiahsitikhodijah@yahoo.co.id ${ }^{1}$
}

\begin{abstract}
ABSTRAK
Penelitian ini dilakukan untuk menjawab masalah yang ada yaitu bagaimanakah pengaruh pelaksanaan penagihan pajak terhadap pencairan tunggakan pajak di Kantor Pelayanan Pajak Pratama Palembang Ilir Barat. Tujuannya Untuk mengetahui pengaruh pelaksanaan penagihan pajak terhadap pencairan tunggakan pajak di Kantor Pelayanan Pajak PratamaPalembang Ilir Barat. Penelitian ini menggunakan jenis penelitian deskriptif.. Variabel yang digunakan adalah penagihan pajak dan pencairan tunggakan pajak. Data yang digunakan adalah data primer dan data sekunder. Teknik pengumpulan data yang digunakan dalam penelitian ini adalah kuesioner. Teknik analisis data yang digunakan yaitu menggunakan statistik deskriptif dan statistik inferensial. Analisis statistik inferensial terdiri dari uji asumsi klasik, analisis regresi sederhana, uji koefisien determinasi dan dilanjutkan dengan uji hipotesis ( uji t ). Teknik analisis data dalam penelitian ini dibantu olehstatistical progtam for special science (SPSS). Hasil analisis menunjukkan bahwa penagihan pajak berpengaruh terhadap pencairan tunggakan pajak di Kantor Pelayanan Pajak Pratama Palembang Ilir Barat.
\end{abstract}

Kata kunci: Penagihan Pajak; Pencairan Tunggakan Pajak

\begin{abstract}
This research was conducted to address the existing problem, namely how the influence of the implementation of tax collection on the tax arrears disbursement at Kantor Pelayanan Pajak Pratama Ilir Barat Palembang. This research used a descriptive research. The study was conducted atKPP Pratama llir Barat Palembang. The variables of this research used were a tax collection and disbursement of tax arrears. The data used were a primary data and a secondary data. Data collection technique used in this study was questionnaires. The data analysis techniques used were a descriptive statistics and inferential statistics. Inferential statistical analysis consisted of the classical assumption test, simple regression analysis, the coefficient of determination test and continued with the hypothesis test ( $t$ test). Data analysis techniques in this study were assisted by SPSS. The results of the analysis showed that tax collection influenced the disbursement of tax arrears at KPP Pratama Ilir Barat Palembang.
\end{abstract}

Keywords: Tax Collection; Tax Arrears Disbursment 


\section{PENDAHULUAN}

Pajak merupakan salah satu bentuk pendapatan negara yang menyumbang persentase terbesar dibandingkan dengan sektor-sektor pendapatan lain seperti minyak dan gas (migas) serta non-migas. Keberhasilan suatu negara dalam mengumpulkan pajak dari warga negaranya dipastikan akan bermanfaat bagi stabilitas ekonomi negara yang bersangkutan. Kesinambungan penerimaan negara dari sektor pajak diperlukan karena penerimaan pajak merupakan sumber utama penerimaan anggaran pendapatan dan pembelanjaan negara (APBN). Untuk menjamin hal tersebut, kepatuhan wajib pajak merupakan salah satu kunci keberhasilan pemerintah dalam menghimpun penerimaan pajak, bukan dengan sekedar menonjolkan aspek pemungutan pajak yang bersifat "memaksa", namun diikuti dengan serangkaian regulasi, prosedur dan pelayanan administrasi yang jelas dan berkelas (Farouq, 2018) .

Dalam Undang-Undang Nomor 19 tahun 1997 sebegaimana telah diubah dengan Undang-Undang Nomor 19 tahun 2000, Penagihan Pajak merupakan : "Serangkaian tindakan agar Penanggung Pajak melunasi utang pajak dan biaya penagihan pajak dengan menegur atau memperingatkan, melaksanakan penagihan seketika dan sekaligus, memberitahukan surat paksa, mengusulkan pencegahan, melaksanakan penyitaan, melaksanakan penyanderaan dan menjual barang yang disita" (Aditya, 2019 ). Sesuai definisi tersebut penagihan pajak pada intinya merupakan serangkaian tindakan dengan tujuan agar penaggung pajak melunasi utang pajak dan biaya penagihan pajak. Tindakan yang dapat dilakukan terdiri atas : menegur atau memperingatkan, penagihan seketika dan sekaligus, memberitahukan surat paksa, mengusulkan pencegahan, melaksanakan penyitaan, melaksanakan penyanderaan dan menjual barang yang telah disita.

Surat paksa adalah suatu ketetapan tertulis oleh pejabat pajak yang berwewenang yang memuat perintah kepada WP yang namanya tertulis didalam SP itu untuk membayar lunas pajak-pajak yang disebut dalam SP itu dalam jangka waktu yang ditentukan dalam SP itu dengan ancaman sita apabila pembayaran tidak dilakukan (Muda, 2005) .

Surat Paksa diterbitkan bila : (1) Sampai dengan tanggal jatuh tempo pembayaran dan setelah Surat Teguran atau Surat Peringatan atau surat lain yang sejenis diterbitkan Penanggung Pajak tidak melunasi utang pajak yang ditagih dengan STP atau SKPKB atau SKPKBT atau surat keputusan pembetulan atau surat keputusan keberatan atau putusan Banding, (2) Penanggung Pajak telah ditagih seketika dan sekaligus, (3) Penanggung Pajak tidak memenuhi ketentuan sebagaimana tercantum dalam keputusan persetujuan angsuran atau penundaan pembayaran pajak (Muda, 2005)

Sebelum diterbitkan surat paksa terlebih dahulu dikeluarkan surat teguran atau surat peringatan. Surat teguran atau surat peringatan atau surat lain yang sejenis adalah surat yang diterbitkan oleh pejabat penagihan ( pajak/bea/cukai) untuk menegur atau memperingatkan wajib pajak untuk melunasi utang pajaknya. Surat teguran atau surat peringatan tidak di terbitkan terhadap penanggung pajak yang utang pajaknya telah disetujui untuk mengangsur atau menunda pembayaran pajak (Bustamar, 2017) .

Pencairan Tunggakan Pajak Merupakan Pembayaran yang dilakukan dengan menggunakan Surat Setoran Pajak yang digunakan untuk pelunasan piutang pajak dan diajukannya keberatan atau banding sehingga mengakibatkan berkurangnya jumlah piutang pajak serta jika penanggung pajak sudah meningal dunia dan berpindah tempat tinggal maka piutang pajak tersebut akan dihapuskan karena penaggung pajak sudah tidak ada atau tidak dapat ditemukan lagi (Waluyo, 2013).

Direktorat Jendral Pajak mengatakkan Pencairan piutang pajak pada 2018 tercatat senilai Rp103,36 triliun atau 156,61\% dari target Rp66 triliun. Persentase capaian itu tercatat mengalami penurunan dibandingkan tahun sebelumnya yang mencapai 187,95\%. (Redaksi DDTCNews | Kamis, 16 Mei 2019 | 16:10 WIB ) 
Tabel 1, penerimaan pajak di kantor pelayanan pajak pratama Palembang ilir barat pada tahun 2014-2018.

\begin{tabular}{llrr}
\hline Tahun Pajak & Target & \multicolumn{1}{c}{ Realisasi } & Pencapaian \\
\hline 2014 & $707,805,553,926$ & $760,566,803,069$ & $107.45 \%$ \\
2015 & $1,087,012,594,020$ & $959,707,546,314$ & $88,29 \%$ \\
2016 & $1,353,692,811,993$ & $1,154,568,018,476$ & $85.29 \%$ \\
2017 & $1,407,583,325,000$ & $1,267,059,009,991$ & $90.02 \%$ \\
2018 & $1,524,675,629,000$ & $1,480,690,166,231$ & $97.11 \%$ \\
\hline
\end{tabular}

Sumber : KPP Pratama Palembang Ilir Barat

Tabel 1 menunjukkan bahwa penerimaan pajak di KPP Palembang Ilir Barat mengalami fluktuasi. Hal ini dapat dilihat pada penerimaan pajak pada tahun 2014-2018. Pada tahun 2014 penerimaan pajak melebihi dari target yang telah ditentukan yaitu sebesar 52.761.249.143, kemudian pada tahun 2015 selisih antara target yang telah ditetapkan dan realisasinya yaitu berjumlah sebesar 127.305.047.706. Pada tahun 2016 selisih antara target yang telah ditetapkan dan realisasinya berjumlah 199.124.793.517. Pada tahun 2017 selisih antara target yang telah ditetapkan dan realisasinya berjumlah 140.524.315.009. Sedangkan pada tahun 2018 selisih antara target yang telah ditetapkan dan realisasinya berjumlah 43.985.462.769. namun walaupun pencapaian meningkat tetapi tidak mencapai target yang telah ditetapkan. Hal ini dapat mengindikasikan penagihan pajak yang kurang optimal sehingga jumlah pencairan tunggakan pajak menjadi kurang optimal juga.

Tabel 2. Jumlah Surat Teguran Dan Surat Paksa dan Hasil / Realisasi Penerimaan Tunggakan Tahun 2016 - 2018

\begin{tabular}{lccc}
\hline \multicolumn{1}{c}{ Permintaan Data } & \multicolumn{2}{c}{ Tahun } \\
\cline { 2 - 4 } & $\mathbf{2 0 1 6}$ & $\mathbf{2 0 1 7}$ & $\mathbf{2 0 1 8}$ \\
\hline Jumlah Surat Teguran dan Surat Paksa & 1,473 & $\mathbf{4 , 7 5 0}$ & 5,232 \\
\hline Hasil / Realisasi Penerimaan & & & \\
$\begin{array}{l}\text { Tunggakan dengan surat Teguran } \\
\text { dan Surat paksa }\end{array}$ & & & \\
\hline
\end{tabular}

Sumber : KPP Pratama Palembang Ilir Barat

Tabel 2 menunjukkan bahwa setiap tahunnya jumlah Surat Teguran dan Surat Paksa yang dikeluarkan oleh KPP Pratama Palembang Ilir Barat meningkat, dan Hasil/ Realisasi Penerimaan Tunggakan dengan Surat Teguran dan Surat Paksa selalu mengalami penurunan.

Beberapa penelitian sebelumnya yang telah dilakukan oleh Fitrisyah (2014); Dina et al.(2016); Walewangko (2015); Sastradipraja (2015) melakukan penelitian dengan judul yang serupa dan didapatkan hasil yang sama bahwa penagihan pajak berpengaruh signifikan terhadap pencairan tunggakan pajak di KPP Pratama Palembang Ilir Barat.

Berdasarkan latar belakang yang telah dipaparkan diatas jadi dapat dirumuskan masalah dalam penelitian ini ialah Seberapa besar pengaruh pelaksanaan penagihan pajak terhadap pencairan tunggakan pajak di Kantor Pelayanan Pajak Pratama Palembang Ilir Barat. Yang bertujuan untuk mengetahui pengaruh pelaksanaan penagihan pajak terhadap pencairan tunggakan pajak di Kantor Pelayanan Pajak Pratama Palembang Ilir Barat. Manfaat penelitian ini yakni dapat menjadi masukan untuk kantor pelayanan pajak pratama palembang ilir barat dalam upaya peningkatan kebijakan penagihan pajak sehingga bisa meminimkan jumlah tunggakan pajak, dan Hasil penelitian ini diharapkan dapat menjadi referensi tambahan, menambah ilmu pengetahuan, serta dapat dijadikan acuan atau kajian bagi penulisan di masa yang akan datang. 


\section{KAJIAN LITERATUR DAN PENGEMBANGAN HIPOTESIS}

\section{Penagihan Pajak}

Dalam Undang-Undang Nomor 19 tahun 1997 sebegaimana telah diubah dengan Undang-Undang Nomor 19 tahun 2000, Penagihan Pajak merupakan : "Serangkaian tindakan agar Penanggung Pajak melunasi utang pajak dan biaya penagihan pajak dengan menegur atau memperingatkan, melaksanakan penagihan seketika dan sekaligus, memberitahukan surat paksa, mengusulkan pencegahan, melaksanakan penyitaan, melaksanakan penyanderaan dan menjual barang yang disita" . Penagihan Pajak adalah suatu tindakan yang dilakukan oleh Direktorat Jendral Pajak untuk wajib pajak yang tidak mematuhi kewajiban perpajakannya (Anang, 2011); (Bustamar, 2017 ); (Aditya , 2019 ); (Chairil, 2014 ). Penagihan pajak dapat dilakukan dengan Surat Teguran dan Surat Paksa ( Siti ,2017), Andi (2014); (Muda 2005); (Damas ,2017); (Bustamar, 2017); (Muda ,2005); (Rimsky, 2005); (Ilyas dan Suhartono, 2012).

\section{Pencairan Tunggakan Pajak}

Pencairan Tunggakan Pajak adalah Jumlah yang dibayarkan wajib pajak atas Tunggakan Pajaknya karena merupakan pajak yang belum dilunasi termasuk sanksi administrasi berdasarkan surat tagihan pajak yang didalamnya terdapat pokok pajak yang terhutang (Waluyo, 2013); (Yustinus, 2010); (Siti, 2017) . Pengukuran pencairan tunggakan pajak ialah jumlah pencairan atas tunggakan pajak (Waluyo, 2013), ( Yustinus, 2010); ( Siti, 2017).

\section{Pengaruh Pelaksanaan Penagihan Pajak Terhadap Pencairan Tunggakan Pajak}

Dalam Undang-Undang Nomor 19 tahun 1997 sebegaimana telah diubah dengan Undang-Undang Nomor 19 tahun 2000, Penagihan Pajak merupakan : "Serangkaian tindakan agar Penanggung Pajak melunasi utang pajak dan biaya penagihan pajak dengan menegur atau memperingatkan, melaksanakan penagihan seketika dan sekaligus, memberitahukan surat paksa, mengusulkan pencegahan, melaksanakan penyitaan, melaksanakan penyanderaan dan menjual barang yang disita."(Aditya, 2019).

Salah satu tindakan penagihan pajak adalah dengan pemberitahuan surat teguran dan surat paksa . Bustamar, (2017) menjelaskan dasar penagihan pajak adalah surat ketetapan pajak yaitu : surat tagihan pajak ,surat ketetapan pajak kurang bayar, surat ketetapan pajak kurang bayar tambahan, dan surat keputusan pembetulan, surat keputusan keberatan, putusan banding, serta putusan peninjauan kembali yang menyebabkan jumlah pajak yang masih harus dibayar bertambah dibidang perpajakan.

Penagihan pajak dengan surat teguran adalah tindakan awal dari proses penagihan pajak aktif. Surat teguran di kirim ke wajib pajak bertujuan untuk menegur atau memperingatkan wajib pajak agar melunasi tunggakan pajaknya (Ilyas dan Suhartono, 2012). Penerbitan surat teguran dilakukan sebagai langkah dari penagihan pajak dimana apabila penanggung pajak tidak ada upaya untuk melunasi utang pajaknya sampai dengan tanggal jatuh tempo pembayaran (Djoko, 2010). Surat Paksa adalah surat yang diterbitkan apabila 21 hari setelah jatuh tempo surat teguran penanggung pajak tidak melunasi utang pajaknya. Penagihan pajak aktif meliputi surat tagihan pajak, surat ketetapan pajak, surat teguran dan surat paksa yang bersifat Wajib pajak untuk mencairkan tunggakan pajaknya (Sumarsono, 2007) Jika penagihan aktif dijalankan secara terus menerus, maka akan meningkatkan pencairan tunggakan pajak (Ramos, 2015. Selain untuk meningkatkan kepatuhan wajib pajak tujuan penagihan pajak dengan surat paksa adalah untuk meningkatkan pencairan tunggakan pajak (Gatot, 2009).

$H_{1}$ : Terdapat pengaruh yang signifikan antara pelaksanaan penagihan pajak terhadap pencairan tunggakan pajak di Kantor Pelayanan Pajak Pratama Palembang Ilir Barat 


\section{METODE}

Jenis penelitian yang digunakan peneliti dalam penelitian ini adalah deskriptif karena peneliti akan menggambarkan seberapa besar pengaruh pelaksanaan penagihan pajak terhadap pencairan tunggakan pajak di KPP Pratama Palembang Ilir Barat. Objek dari penelitian ini adalah Kantor Pelayanan Pajak Pratama Palembang Ilir Barat yang beralamat di Jl. Tasik, Talang Semut, Kambang Iwak Palembang Kec. Bukit Kecil, Kota Palembang, Sumatera Selatan 30135. Data yang digunakan dalam penelitian ini ialah data primer dan data sekunder. Metode pengumpulan data yang digunakan ialah kuesioner dengan cara menyebar pertanyaan melalui google form kepada wajib pajak yang terdaftar di KPP Pratama Palembang Ilir Barat. Populasi dalam penelitian ini adalah wajib pajak yang terdaftar di KPP Pratama Palembang Ilir Barat. Jumlah sampel yang diambil dalam penelitian ini 100 wajib pajak yang terdaftar di KPP Pratama Palembang Ilir Barat. Teknik pengumpulan sampel yang digunakan dalam penelitian ini menggunakan Teknik sample random sampling. Untuk menentukan ukuran sampelnya digunakan dengan rumus slovin. Pengujian data yang digunakan ialah uji validitas dan uji reliabilitas. Teknik analisis data dibantu ole SPPS 25, dengan melakukan beberapa uji statistik yaitu (1) statistik deskriptif dan (2) statistik inferensial. Penelitian ini menggunakan model analisis regresi linier sederhana. uji regresi linier sederhana adalah hubungan secara linier antara satu variable independent $(x)$ dengan variable dependend ( $\mathrm{y}$ ) (Sugiyono, 2018). Analisis ini untuk mengetahui adakah pengaruh antara variable independent dengan variable dependent apakah ada pengaruh positif atau negative.

\section{Uji Validitas}

Tabel 3. Penagihan Pajak

\begin{tabular}{lccc}
\hline Butir Pertanyaan & $\boldsymbol{r}_{\text {hitung }}$ & $\boldsymbol{r}_{\text {tabel }}$ & Status \\
\hline 1 & 0,643 & 0,361 & Valid \\
2 & 0,605 & 0,361 & Valid \\
3 & 0,684 & 0,361 & Valid \\
4 & 0,731 & 0,361 & Valid \\
5 & 0,695 & 0,361 & Valid \\
6 & 0,660 & 0,361 & Valid \\
7 & 0,654 & 0,361 & Valid \\
8 & 0,676 & 0,361 & Valid \\
9 & 0,739 & 0,361 & Valid \\
10 & 0,618 & 0,361 & Valid \\
\hline
\end{tabular}

Sumber : Hasil Pengolahan Data, 2020

Berdasarkan hasil pengujian validitas yang menunjukkan butir pernyataan dari variabel penagihan pajak yang telah diuji kevaliditasannya dinyatakan valid dan dapat digunakan sebagai alat pengumpulan data.

Tabel 4. Pencairan Tunggakan Pajak

\begin{tabular}{lccc}
\hline Butir Pertanyaan & $\boldsymbol{r}_{\text {hitung }}$ & $\boldsymbol{r}_{\text {tabel }}$ & Status \\
\hline 1 & 0,592 & 0,361 & Valid \\
2 & 0,815 & 0,361 & Valid \\
3 & 0,803 & 0,361 & Valid \\
4 & 0,756 & 0,361 & Valid \\
5 & 0,734 & 0,361 & Valid \\
\hline
\end{tabular}

Sumber : Hasil Pengolahan Data, 2020 
Berdasarkan hasil pengujian validitas yang menunjukkan butir pernyataan dari variabel pencairan tunggakan pajak yang telah diuji kevaliditasannya dengan demikian, seluruh butir pernyataan variabel pencairan tunggakan pajak $(\mathrm{Y})$ dinyatakan valid dan dapat digunakan sebagai alat pengumpulan data.

\section{Uji Reliabilitas}

Tabel 5. Uji Reliabilitas

\begin{tabular}{cccc}
\hline Variabel & Croanbach's Alpha Item & Croanbach's Alpha & Keterangan \\
\hline$X$ & 0,858 & 0,6 & Reliabel \\
Y & 0,796 & 0,6 & Reliabel \\
\hline
\end{tabular}

Sumber : Hasil Pengolahan Data, 2020

Berdasarkan hasil pengujian reliabilitas, maka nilai Croanbach's Alpha dari masing-masing variabel lebih besar dari Croanbach's Alpha. Maka dari itu, seluruh butir pernyataan dalam masing-masing variabel dinyatakan reliabel dan dapat digunakan sebagai alat ukur variabel.

\section{Statistik Deskriptif}

Tabel 6. Analisis Statistik Deskriptif

\begin{tabular}{llccccc}
\hline & N & Minimum & Maximum & Mean & Std. Deviation & Variance \\
\hline Total_X & 100 & 28,00 & 50,00 & 40,7100 & 5,10554 & 26,067 \\
Total_Y & 100 & 9,00 & 25,00 & 20,7200 & 2,64796 & 7,012 \\
Valid N & & & & & \\
(listwise) & 100 & & & & & \\
\hline
\end{tabular}

Sumber :Hasil Pengolahan Data, 2020

Hasil tersebut menjelaskan bahwa hasil uji statistic suatu data yang dilihat dari nilai rata-rata (mean) standar deviasi dan jumlah $\mathrm{n}$ dari penelitian ini yaitu 100, nilai 100 itu diperoleh dari jumlah responden yang dijadikan sampel penelitian. Pada variabel penagihan pajak memiliki nilai rata-rata 40,71 yang tergolong kriteria tinggi. Pada variabel pencairan tunggakan pajak memiliki nilai rata-rata 20,72 yang tergolong kriteria sangat rendah.

Berdasarkan hasil analisis deskriptif yang telah diuji pada variabel penagihan pajak dan pencairan tunggakan pajak, maka rata-rata (mean) tertinggi yaitu pada variabel penagihan pajak dengan nilai ratarata (mean) 40,71 yang tergolong kriteria tinggi. 


\section{Statitik Inferensial}

\section{Uji Normalitas}

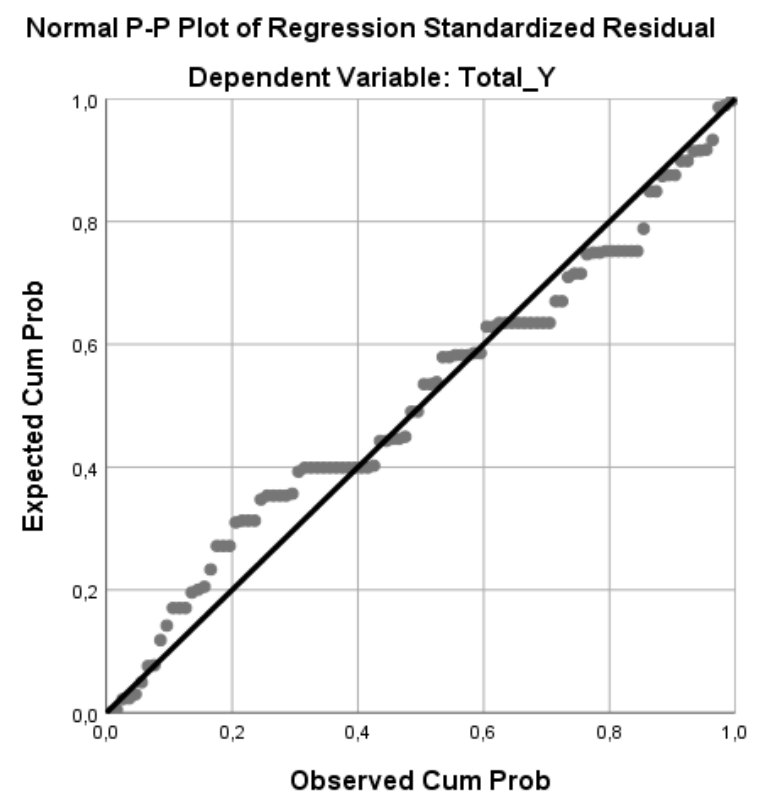

Gambar 1. Uji Normalitas

Dapat disimpulkan bahwa grafik normal $p$-p plot of regression standardized residual dependent variabel pencairan tunggakan pajak terlihat titik-titik menyebar disekitar garis diagonal dan penyebarannya mengikut arah diagonal, dengan demikian grafik tersebut telah menunjukkan bahwa model regresi layak digunakan karena telah memenuhi asumsu normalitas.

\section{Uji Multikolinearitas}

Tabel 7. Hasil Uji Multikolinearitas

\begin{tabular}{|c|c|c|}
\hline \multirow{2}{*}{ Model } & \multicolumn{2}{|c|}{ Collinearity Statistics } \\
\hline & Tolerance & VIF \\
\hline \multicolumn{3}{|l|}{ (Constant) } \\
\hline Penagihan Pajak ( X) & 1,000 & 1,000 \\
\hline
\end{tabular}

Sumber : Hasil Pengolahan Data,2020

Berdasarkan hasil uji multikolinearitas didapat bahwa tollerance tiap variabel lebih besar dari 0,10 dan nilai VIF lebih kecil dari 10, maka dapat disimpulkan bahwa tidak terjadi multikolinearitas antara variabel bebas dalam penelitian ini sehingga model regresi tersebut layak untuk digunakan. 


\section{Uji Heterokedastisitas}

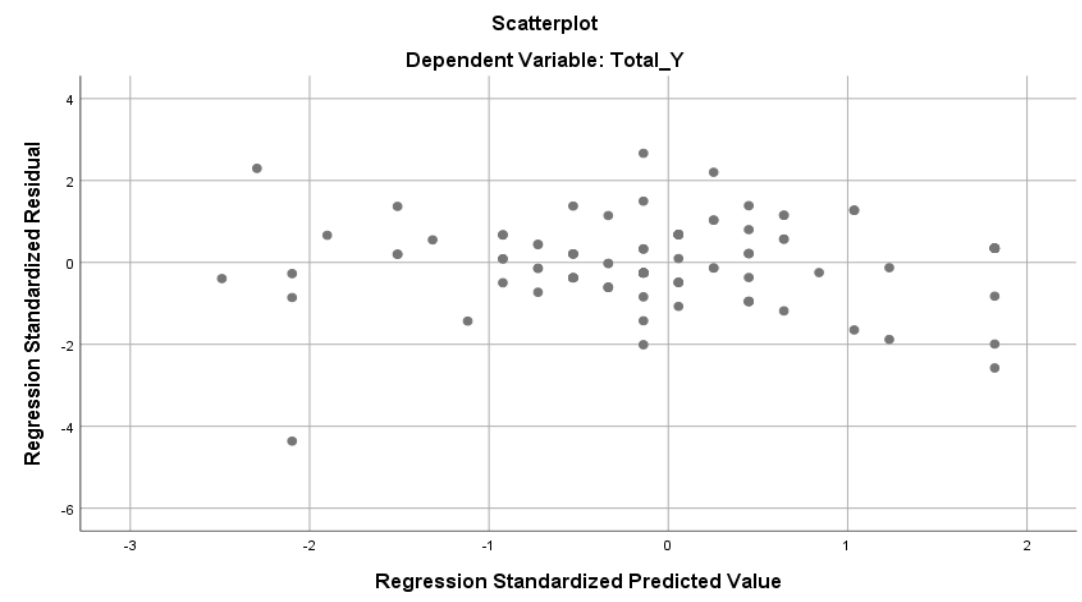

Gambar 2. Hasil Uji Heteroskedastisitas

Berdasarkan gambar diatas dapat diketahui bahwa titik-titik tidak membentuk pola yang jelas, dan titiktitik menyebar diatas dan dibawah angka 0 pada sumbu Y. Jadi dapat disimpulkan bahwa tidak terjadi masalah heteroskedastisitas.

\section{Uji Regresi Linear Sederhana}

Tabel 8. Hasil Uji Regresi Linear Sederhana

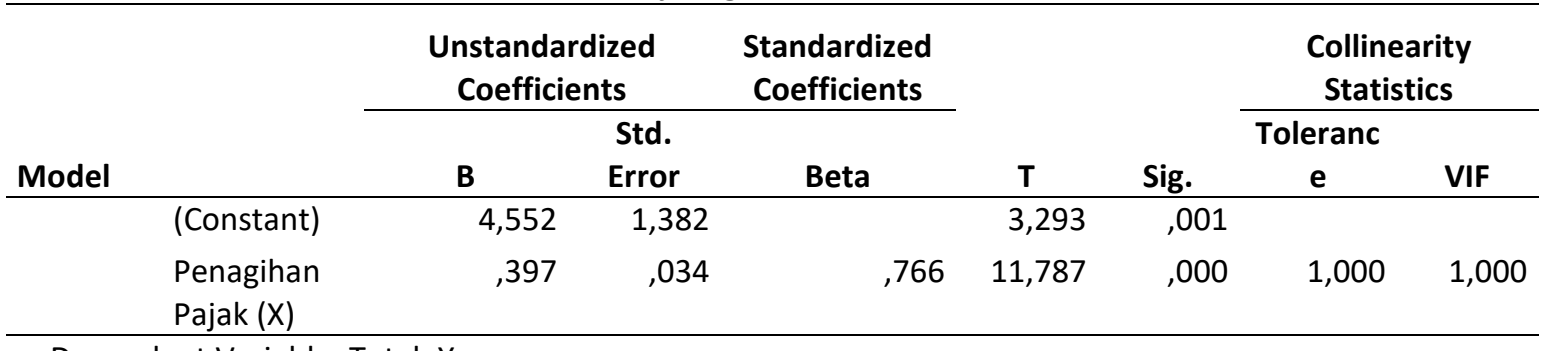

a. Dependent Variable: Total_Y

Sumber : Hasil Pengolahan Data,2020

Hasil ouput SPSS di atas menunjukkan bahwa hasil uji hipotesis secara regresi linier sederhana diketahui nilai $t_{\text {hitung }}$ untuk penagihan pajak 11,787 . Berdasarkan kriteria pengujian nilai $t_{\text {tabel }}$ untuk penagihan pajak 0,000.

\section{Uji Koefisien Determinasi}

Tabel. 9 Hasil Uji Koefisien Determinasi

\begin{tabular}{ccccc} 
Model & $\mathbf{R}$ & R Square & Adjusted R Square & Std. Error of the Estimate \\
\hline 1 &, $766^{\text {a }}$ &, 586 &, $582 \mathrm{n}$ & 1,71169 \\
\hline
\end{tabular}

\footnotetext{
a. Predictors: (Constant), Total_X
}

b. Dependent Variable: Total_Y

Sumber : Hasil Pengolahan Data, 2020 
Output diperoleh angka R Square sebesar 0,586 atau 58,6\%. Hal ini mengindikasikan bahwa kontribusi variabel penagihan pajak dalam pencairan tunggakan pajak adalah sebesar $58,6 \%$ sedangkan $41,4 \%$ lainnya ditentukan oleh faktor lain diluar model yang tidak dideteksi.

\section{Pembahasan}

Hasil penelitian dan uji hipotesis yang dilakukan menunjukkan bahwa penagihan pajak berpengaruh terhadap pencairan tunggakan pajak di kantor pelayanan pajak pratama palembang ilir barat. Penulis dapat membahas mengenai variabel yang diteliti yaitu penagihan pajak dengan pengukuran menggunakan surat teguran dan surat paksa dan pencairan tunggakan pajak dengan pengukuran realisasi pembayaran tunggakan pajak. Pelaksanaan penagihan pajak dengan surat teguran dan surat paksa di kantor pelayanan pajak pratama palembang ilir barat dilaksanakan dengan cukup baik, berdasarkan data yang diperoleh dari kantor pelayanan pajak pratama palembang ilir barat bahwa telah dilakukan penagihan pajak dengan surat teguran dan surat paksa terhadap wajib pajak yang tidak membayar pajak. Penagihan pajak dengan surat teguran dilakukan setelah wajib pajak tidak membayar pajak setelah tujuh hari tanggal jatuh tempo pembayaran pajak beserta biaya-biaya administrasi lainnya sedangkan penagihan pajak dengan surat paksa dilakukan setelah wajib pajak menerima surat teguran tetapi dalam waktu 21 hari wajib pajak masih belum melunasi utang pajaknya. Penagihan dengan surat teguran dilakukan untuk memaksa wajib pajak melunasi utang pajaknya yang masih tersisa. Besarnya nilai surat paksa jika diiringi dengan realisasi pembayaran tunggakan pajak maka akan mempengaruhi penerimaan pajak dan hal ini akan menambah pendapatan negara.

Hasil penelitian ini sejalan dengan penelitian yang dilakukan oleh Yola (2019) yang mengemukakan bahwa penagihan pajak berpengaruh signifikan terhadap pencairan tunggakan pajak pada KPP Pratama Padang Satu. Hasil ini diketahui nilai t hitung nya sebesar 5,139116 dan tingkat prob. 0,0000 lebih kecil dari 0,05 .

\section{SIMPULAN}

Penagihan pajak berpengaruh terhadap pencairan tunggakan pajak di Kantor Pelayanan Pajak Pratama Palembang Ilir Barat. Bagi Pihak Kantor Pelayanan Pajak Pratama Palembang Ilir Barat hendaknya selalu dilakukan evaluasi terhadap sistem penagihan pajak dengan surat teguran dan surat paksa yang telah diterapkan sehingga wajib pajak lebih mengerti tentang pentingnya pajak dengan seiring melakukan sosialisasi dan himbawan kepada wajib pajak untuk membayar pajak secara tepat waktu sehingga dapat meningkatkan penerimaan pajak. Bagi Wajib Pajak agar membayar kewajiban pajaknya tepat waktu karena akan mempengaruhi penerimaan pajak dan hal ini akan menambah pendapatan negara demi untuk kesejahteraan bersama.

\section{REFERENSI}

Anggoro, D. D. (2017). Pajak daerah dan retribusi daerah. Universitas Brawijaya Press.

Bustamar Ayza, S. H. (2016). Hukum Pajak Indonesia. Kencana.

Direktorat Jendral Pajak (2019) Pencairan Piutang Pajak Belum Optimal. 16 Mei 2019. https://news.ddtc.co.id/pencairan-piutang-pajak-belum-optimal-ini-alasan-djp-15912

Faisal, G. S. (2009). How to be A Smarter Taxpayer: Bagaimana menjadi Wajib Pajak. Grasindo.

Farouq, M. (2018). Hukum Pajak di Indonesia. Prenada Media. 
Fatmadika, D., Susilo, H., \& Agusti, R. R. (2016). Pengaruh Surat Teguran Terhadap Pencairan Tunggakan Pajak Dengan Surat Paksa Sebagai Variabel Intervening (Studi Pada Kantor Pelayanan Pajak Pratama Malang Utara). Jurnal Mahasiswa Perpajakan, 9(1).

Fitrisyah, A., \& Ermadiani, E. (2014). Pengaruh Penagihan Pajak dengan Surat Teguran dan Surat Paksa terhadap Penerimaan Tunggakan Pajak Badan pada Kpp Pratama Palembang Seberang Ulu. Akuntabilitas, 8(1), 115-124.

Imam, G. (2016). Aplikasi Analisis Multivariete dengan program IBM SPSSS 23.

Indriantoro, N., \& Supomo, B. (2002). Metodologi Penelitian Bisnis. Yogyakarta: BPFE.

Judisseno, R. J. Pajak \& Strategi Bisnis (Revisi). Gramedia Pustaka Utama.Romie Priyastama( 2017 ) Buku Sakti Kuasai SPSS Pengelolaan Data dan Analisis Data. Penerbit : Start Up

Kurniawan, A. M. (2011). Upaya Hukum Terkait dengan Pemeriksaan, Penyidikan, dan Penagihan Pajak. Yogyakarta: Graha IImu.

Mamusu, R. F., \& Elim, I. (2017). Analisis Efektivitas Penagihan Pajak Aktif Dengan Menggunakan Surat Teguran Dan Surat Paksa Di Kpp Pratama Kabupaten Poso. Jurnal EMBA: Jurnal Riset Ekonomi, Manajemen, Bisnis dan Akuntansi, 5(2).

Markus, M., \& Lalu, H. (2005). Perpajakan Indonesia. Gramedia Pustaka Utama.

Mulyono, D. (2016). Panduan Brevet Pajak: Akuntansi Pajak dan Ketentuan Umum Perpajakan.

Pohan, C. A., \& Perpajakan, P. K. P. (2014). Teori dan Konsep Hukum Pajak. Cetakan I, Mitra Wacana Media, Jakarta.

Purwana, A. S. (2019). Penagihan Pajak dengan Surat Paksa di Bidang Kepabeanan dan Cukai. Uwais Inspirasi Indonesia.

Saputri, H. A., \& Sastradipraja, U. (2015). Pengaruh Penagihan Pajak Dengan Surat Teguran Dan Surat Paksa Terhadap Efektivitas Pencairan Tunggakan Pajak (studi Kasus Pada Kpp Pratama Bandung Cibeunying Periode 2010-2014). eProceedings of Management, 2(2).

Sari, S. N., Afifah, N., \& Akdam, F. (2020). Pengaruh Sanksi Adminsitrasi Perpajakan Terhadap Pencairan Tunggakan Pajak Pada KPP Madya Makassar. Jurnal Analisa Akuntansi dan Perpajakan, 3(2).

Sugiyono (2018) Metode Penelitian Bisnis: Pendekatan Kuantitatif, Kualitatif, Kombinasi, dan R\&D. Bandung: Alfabeta.

Sumarsono (2007) Perpajakan Pendekatan Komprehensif. Jakarta: Salemba Empat.

Walewangko, T. L. U. (2016). Analisis Efektivitas pencairan Tunggakan Pajak Aktif dengan Tindakan Penyitaan Terhadap Pencairan Tunggakan Pajak di KPP Pratama Ambon. Jurnal EMBA: Jurnal Riset Ekonomi, Manajemen, Bisnis dan Akuntansi, 4(1).

Waluyo (2013) Perpajakan Indonesia Edisi 11. Jakarta. Salemba Empat.

Wirawan, B. I., \& Suhartono, R. (2012). Perpajakan: Pembahasan Lengkap Berdasarkan Perundangundangan dan Aturan Pelaksanaan Terbaru. 